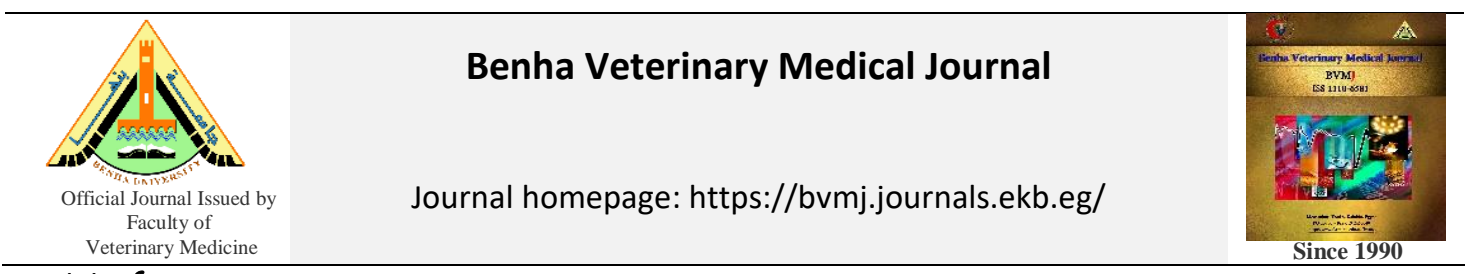

Original Paper

\title{
Corynebacterium Pseudotuberculosis infection in small ruminant and molecular study of virulence and resistance genes in Beni-Suef governorate
}

\author{
Ashraf A. Abd El Tawab ${ }^{1}$, Amira M. Rizk ${ }^{1}$, Samia. E. Afifi ${ }^{2}$ and Shimaa R. Mohamed ${ }^{2}$ \\ ${ }^{1}$ Bacteriology, Immunology and Mycology Department, Faculty of Veterinary Medicine, Benha University, Egypt. \\ ${ }^{2}$ Directorate of Veterinary Medicine, Beni-Suef, Egypt.
}

\section{ARTICLE INFO}

\begin{tabular}{l}
\hline Keywords \\
Beni Suef \\
Corynebacterium \\
Pseudotuberculosis \\
Goat \\
Resistance genes \\
Sheep \\
Received $26 / 10 / 2019$ \\
Accepted $04 / 11 / 2019$ \\
Available On-Line \\
12/05/2020
\end{tabular}

\begin{abstract}
Small ruminant producers sustain a considerable economic loss in many countries due to herd infection with Caseous lymphadenitis (CLA), a contagious chronic pyogenic disease of sheep and goat. This disease is caused by Corynebacterium pseudotuberculosis. In this study we investigated the prevalence of CLA in sheep and goat in Beni-Suef Governorate from the period of (March 2016 - April 2017) and examined the status of C. pseudotuberculosis drug resistance genes. Out of two hundred animals (165) sheep and (35) goat affected with external abscess, abscesses swabs were examined for presence of C. pseudotuberculosis. Prevalence of C. pseudotuberculosis was $13.9 \%$ in sheep and $8.6 \%$ in goat being mainly in the mandibular $56.3 \%$, parotid $35.1 \%$ and prescapular $4.8 \%$. Antibiotic sensitivity of the C. pseudotuberculosis showed its high susceptibility to quinolone, phenicol and sulpha and higher resistant to $\beta$-lactames, aminoglycosides and lincosamides. PCR amplification of the antibiotic resistance genes revealed the presence of $\beta$-lactames resistance gene (bla) in $40 \%$ of the isolates, aminoglycosides resistance gene (aadA2) in $42 \%$ of the isolates. The current study revealed the change of the C. pseudotuberculosis susceptibility to the antimicrobial effect than previous report. These results may necessitate the reconsideration of the general C. pseudotuberculosis management protocol based on the current situation which also seem to be specific for each locality depending on the previous exposure to antibiotic regimes for controlling C. pseudotuberculosis or other microorganism.
\end{abstract}

\section{INTRODUCTION}

Small ruminant producers sustain a considerable economic loss in many countries due to herd infection with a highly contagious chronic pyogenic disease of sheep and goat (Dorella et al., 2006). This is the so called Caseous lymphadenitis disease (Fontaine and Baird 2008; Windsor 2011) caused by Corynebacterium pseudotuberculosis, a gram-positive bacterium well known to be facultative intracellular, multiplying within macrophages (Dorella et al., 2006). C. pseudotuberculosis produces caseous lymphadenitis in goats and sheep (Baird and Fontaine, 2007), edematous skin disease in buffalo (Selim, 2001), ulcerative lymphangitis in horse (Baraúna et al., 2017).

Diseases caused by infection with these bacteria is expressed in two forms, external form occurs mostly in the superficial lymph node and start as an abscess that convert later on to pyogranulomas lesion ranging in size from millimeters to centimeters (Baird and Fontaine, 2007). Meanwhile, visceral form is none clinically detectable but causes progressive weight loss, respiratory disorders and chronic recurrent ruminal tympany (Santana et al., 2016). The poor response of this disease to treatment and its ability to stay in the environments and difficulty of recognizing sub-clinically infected animals make it is very hard to control the spread of the disease between animals after its first introduction into a flock (Williamson, 2001) and make its eradication from an infected herd or area is seem to be a dream (Soares et al., 2013). Moreover, its zoonotic importance became of interest as clinical cases of human lymphadenitis were reported to occur through consumption of raw milk from infected sheep or through direct contact of persons having a cracked skin with external open abscess in animal (Peel et al., 1997).

The prevalence of the disease between small ruminant in Egypt in different geographical areas is still dissimilar. A prevalence of $6.7 \%$ was reported in El-Gharbia Governorate (Oreiby et al., 2014), while in a previous study, bacteriological examination of sheep in slaughter house was reported to be $25 \%$ with CLA in El-Gharbia

* Corresponding author: Dr. Amira Mohamed Rizk. Bacteriology, Immunology and Mycology Department, Faculty of

Veterinary Medicine, Benha University, Egypt. 
Governorate (Al-Gaabary et al., 2010) and prevalence of $C$. pseudotuberculosis was $41.3 \%$ in Menoufia governorate (Abdelazeem Algammal, 2016).

The aim of the current study was to investigate the prevalence of CLA in sheep and goat in Beni-Suef governorate and to elucidate the virulence gene in the isolates and further to examine the status of drug resistance genes in the isolated C. pseudotuberculosis in this special geographical area.

\section{MATERIAL AND METHODS}

Ethical approval:

All samples were taken according to standard sample collection procedure without putting any stress on the animal. The current study was approved by the Ethical Committee for Medical Research at the Faculty of Veterinary Medicine, Benha University, and Animal Care Guidelines of the General Organization for Veterinary Services, Egypt.

\subsection{Sampling and isolation:}

Two hundred swabs were collected from (165) sheep and (35) goat abscesses in superficial lymph nodes in Beni-Suef Governorate. The outer surfaces of the affected lymph nodes were cleaned, disinfected by $70 \%$ ethanol and incised using sterile blade. The abscesses were squeezed, and swabs were taken from the inner part (Fig. 1).

The swabs were streaked in duplicate for each sample onto plates of brain heart infusion (BHI) agar (Oxoid) and 5\% sheep blood agar (Oxoid) and both plates supplemented with fosfomycin (200 mg/litter) and nalidixic acid (4 $\mathrm{mg} / \mathrm{L})$, then incubated for (24-48 hours) at $37^{\circ} \mathrm{C}$.

Colonies were examined for color, consistency and stained with Gram's stain. Colonies which appeared Gram positive, non-spore forming coccobacilli were selected for subculturing to obtain a pure culture. These colonies were picked up and transferred into semisolid nutrient agar medium for further investigation.

The isolated colonies were tested for catalase, urease activities, nitrate reduction, gelatin liquefaction, sugar fermentation, synergistic hemolytic activity with Rhodococcus equi (CAMP test) and Reverse CAMP test.

\subsection{Antibiotic sensitivity test}

Antimicrobial sensitivity patterns of C. Pseudotuberculosis isolates were determined using the Kirby-Bauerdisk diffusion method (Quinn et al., 1994). The isolates were tested for susceptibility to 9 antibiotics (Oxoid) (enrofloxacin $(5 \mu \mathrm{g})$, amoxicillin $(10 \mu \mathrm{g})$, amoxicillin/ clavulanic acid $(20 / 10 \mu \mathrm{g})$, trimethoprim-sulfamethoxazole $(1.25 / 23.75 \mu \mathrm{g})$, norfloxacin $(10 \mu \mathrm{g})$, ciprofloxacin $(5 \mu \mathrm{g})$ gentamicin $(10 \mu \mathrm{g})$, florfenicol $(30 \mu \mathrm{g})$ and clindamycin $(2$ $\mu \mathrm{g})$ ).

\subsection{Molecular diagnosis of C. pseudotuberculosis:}

Out of identified C. pseudotuberculosis, 5 selected isolates were grown on BHI agar (Oxoid) for 48 hours at $37{ }^{\circ} \mathrm{C}$ followed by extraction of the bacterial DNA using QIAamp DNA Mini Kit Catalogue no. 51304 according to the manufacturer instructions.
Using the extracted bacterial DNA, virulence gene PLD and drug resistance genes as $\beta$-lactames resistance gene (bla), integron (int) and aminoglycosides resistance gene $(\operatorname{aad} \mathrm{A} 2)$ were amplified using the primers listed in table (1).

Amplification reactions were prepared in $25 \mu 1$ containing PCR master-mix (2X premix) (Emerald GT mastermix, Takara kit) $12.5 \mu \mathrm{l}$, forward and reverse primers $1 \mu \mathrm{l}$, template DNA $6 \mu 1$ completed to $25 \mu 1$ by $4.5 \mu$ l PCR grade water. PCR was performed in T3 Thermal cycler (Biometra), using C. pseudotuberculosis (ATCC 19410) as the control positive (reference strain) while sterile DNAse/RNAse free and Diethyl Pyrocarbonate (DEPC) water was used instead of template DNA as a control negative.

The reaction condition was initial denaturation at $94{ }^{\circ} \mathrm{C}$ for 5 min followed by 35 cycles of denaturation at $94{ }^{\circ} \mathrm{C}$ for 30 sec., annealing (at $56{ }^{\circ} \mathrm{C}$ for $30 \mathrm{sec}$. for PLD, $55^{\circ} \mathrm{C}$ for 30 sec, for int and at $50{ }^{\circ} \mathrm{C}$ for $30 \mathrm{sec}$. for bla and aadA2) and extension at $72{ }^{\circ} \mathrm{C}$ for $30 \mathrm{sec}$. followed by final extension at $72{ }^{\circ} \mathrm{C}$ for $7 \mathrm{~min}$. The PCR was performed using DNase/RNase free DEPC water instead of the template while positive control was performed using DNA template from reference strain $C$. pseudotuberculosis (ATCC 19410).

The amplified PCR products were electrophoresed through 1.5 Agarose gel in TBE buffer in Gel Casting Apparatus (Biometra) for 1 hour against $100 \mathrm{bp}$ DNA ladder (Gel Pilot 100 bp ladder, Cat. no. 239035) supplied from QIAGEN (USA). The DNA bands were stained with Ethidium bromide, visualized using gel documentation system, and the data were analyzed using computer software.

Table 1 Primers used in amplification of C. pseudotuberculosis virulence gene PLD and drug resistance genes beta lactames resistance gene (bla) integron (int) and aminoglycosides resistance gene (aadA2), size of the PCR product and the reference of each primer

\begin{tabular}{|c|c|c|c|}
\hline Gene & Sequence & $\begin{array}{l}\text { Product } \\
\text { size }\end{array}$ & Reference \\
\hline Pld & $\begin{array}{l}\text { ATA AGC GTA AGC AGG GAG CA } \\
\text { ATC AGC GGT GAT TGT CTT CCA GG }\end{array}$ & 203bp & 13 \\
\hline bla & $\begin{array}{l}\text { ATGAAAGAAGTTCAAAAATATTTAGAG } \\
\text { TTAGTGCCAATTGTTCATGATGG }\end{array}$ & 780 bp & $\begin{array}{l}\text { Catalánet al., } \\
2010\end{array}$ \\
\hline Int & $\begin{array}{l}\text { Hep35: TGCGGGTYAARGATBTKGATTT } \\
\text { Hep36: CARCACATGCGTRTARAT }\end{array}$ & 491 bp & $\begin{array}{l}\text { White et al. } \\
2000\end{array}$ \\
\hline $\operatorname{aad} \mathrm{A} 2$ & $\begin{array}{l}\text { TGTTGGTTACTGTGGCCGTA } \\
\text { GATCTCGCCTTTCACAAAGC }\end{array}$ & 622 bp & $\begin{array}{l}\text { Walker } e t \\
\text { al., } 2001\end{array}$ \\
\hline
\end{tabular}

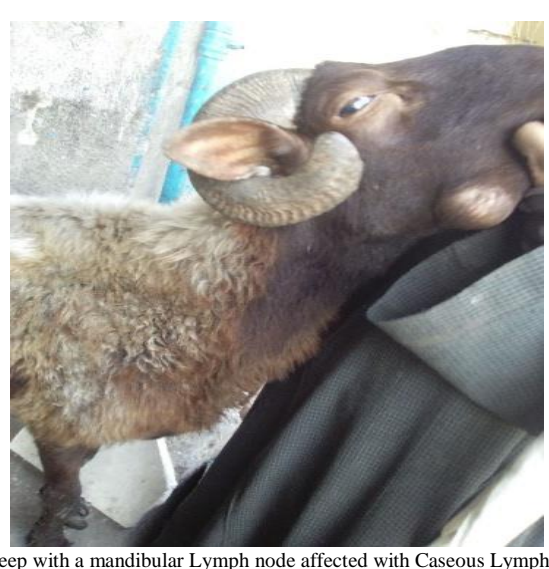

Figure 1 Sheep with a mandibular Lymph node affected with Caseous Lymphadenitis. The outer surfaces of the affected lymph nodes were cleaned, disinfected by $70 \%$ ethanol and incised using sterile blade. The abscesses were squeezed, and swabs were taken from the inner part 


\section{RESULTS}

3.1. Caseous lymphadenitis in sheep and goats:

Isolated C. pseudotuberculosis was 23 out of 165 sheep with abscess reaching (13.9\%) and in goat was 3 out of 35 goats with abscess reaching (8.6\%) with an overall isolation rate (26 out of 200 sheep and goat with abscess) of $(13 \%)$.

3.2. Distribution of C. pseudotuberculosis in sheep and goats' lymph nodes:

Out of 23 affected sheep, the distribution of $C$. pseudotuberculosis in lymph node was Mandibular 10 (43.5\%), Parotid 9 (39.1\%), Prescapular $3(13 \%)$ and finally Prefemoral $1(4.3 \%)$.

The most frequent sites in (3) goats were the Mandibular 1(33.3\%) and Parotid $2(66.7 \%)$. The results in sheep indicates a high rate of infection localized in the Mandibular and Parotid lymph node and a low rate of infection of the Prescapular and Prefemoral lymph node while in goat, the mandibular and parotid lymph node are the only affected meanwhile the Prefemoral and prescapular lymph node of goat are free.

3.3. Bacteriological characters of C. pseudotuberculosis isolates:

All isolates of C. pseudotuberculosis recovered from lymph nodes abscesses were Gram positive coccobacilli to short bacilli, non-sporulated, non-capsulated, non-motile and appeared single, pairs in acute angles (like Chinese letter) and in palisades arrangements. After 48 hours incubation on blood agar, the colonies were white, smooth, opaque, circular, small in size, dry, waxy in appearance and surrounded by narrow zone of beta haemolysis .

The colonies on BHIA, after (48 hours) had the same characters but were larger in size .The colonies were easily pushed across the agar surface and spattered when placed in flame.

CAMP test revealed a distinct zone of synergistic hemolysis appeared around the colonies of $C$. pseudotuberculosis with Rhodococcus equi. Reverse CAMP test was used and all the isolates were reverse CAMP test positive with Staphylococcus aureus.

Biochemical identification: All the isolates were positive for urease, catalase and negative for nitrate reduction, gelatin liquefaction while the results of Sugar fermentation tests were glucose positive, trehalose negative and other sugars were variable results.

3.4. Antimicrobial susceptibility patterns of $C$. pseudotuberculosis recovered from abscess:

A total of 26 C. pseudotuberculosis isolates were tested for susceptibility to 9 antibiotics. As shown in the table (2), the susceptibility pattern of $C$. pseudotuberculosis to antimicrobial agents varied among isolates according to the CLSI 2015. The majority of isolates were highly sensitive to ciprofloxacin $17 \quad(65.4 \%)$ and trimethoprimsulfamethoxazole16 (61.5\%). while, such strains showed high resistance to amoxicillin/clavulanic acid20 (76.9\%).
Table 2 Results of Antimicrobial sensitivity test of C. pseudotuberculosis isolates recovered from sheep and goat external abscess according to the CLSI 2015

\begin{tabular}{lccc}
\hline & \multicolumn{3}{c}{ Corynebacterium pseudotuberculosis } \\
Antimicrobials & $\begin{array}{c}\text { Susceptible } \\
\text { isolates } \\
\text { No. and (\%). }\end{array}$ & $\begin{array}{c}\text { Intermediate } \\
\text { isolates } \\
\text { No. and (\%) }\end{array}$ & $\begin{array}{c}\text { Resistance } \\
\text { isolates } \\
\text { No. and (\%) }\end{array}$ \\
\hline $\begin{array}{l}\text { Enrofloxacin } \\
\begin{array}{l}\text { Amoxicillin } \\
\text { Amoxicillin/Clavulanic }\end{array}\end{array}$ & $11(42.3 \%)$ & 0 & $15(57.7)$ \\
$\begin{array}{l}\text { acid } \\
\text { Trimethoprim- } \\
\text { sulfamethoxazole }\end{array}$ & $12(46.2 \%)$ & 0 & $14(53.8 \%)$ \\
$\begin{array}{l}\text { Norfloxacin } \\
\text { Ciprofloxacin }\end{array}$ & $16(23.1 \%)$ & 0 & $20(76.9 \%)$ \\
$\begin{array}{l}\text { Gentamycin } \\
\text { Florfenicol }\end{array}$ & $12(46.2 \%)$ & $5(19.2 \%)$ & $9(34.6 \%)$ \\
clindamycin & $17(65.4 \%)$ & $3(11.5 \%)$ & $6(23.1 \%)$ \\
\hline
\end{tabular}

3.5. Detection of C. pseudotuberculosis virulence gene (PLd):

Out of the 26 isolates, 5 isolates were selected for investigation of the presence of virulence gene. All selected isolates of $C$. pseudotuberculosis gave positive results for the amplification of PLd gene of $203 \mathrm{bp}$ fragment using oligonucleotides primers specific for $C$. pseudotuberculosis PLD in $100 \%$ of tested isolates (Fig. 2).

3.6. Detection of beta lactamase resistance gene (bla) in C. pseudotuberculosis:

Out of the 26 isolates, 5 isolates were selected for investigation of beta lactamase resistance gene presence. Using oligonucleotides primers specific for $(b l a)$ gene in the selected 5 isolates of C. pseudotuberculosis. Two of the selected isolates (no. 4 and 5) were positive for the amplification of the beta lactames resistance gene (bla) at 780 bp fragment. (Fig. 3)

3.7. Detection of C. pseudotuberculosis integron and aadA2 genes.

Out of the 26 isolates of $C$. pseudotuberculosis, 5 isolates were selected for investigation of the presence of integron, (int) and aminoglycosides (aadA2) resistance genes using oligonucleotides specific primers for each. Amplification of aadA2 gene 622 bp was detected in one isolate( no. 3) while all isolates were negative for integron amplification 491 bp (Fig. 4).

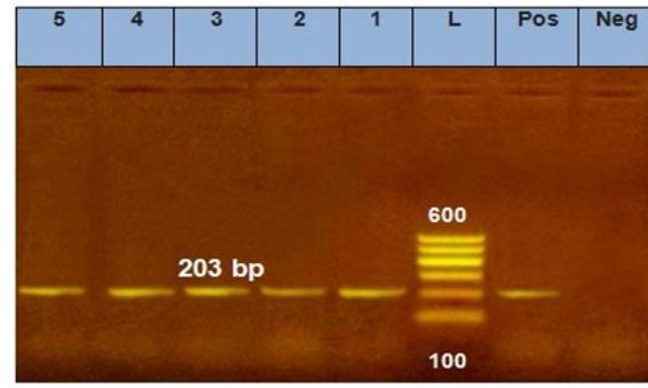

Figure 2 Agarose gel electrophoresis showing amplification product of $\mathrm{C}$ pseudotuberculosis PLD gene performed with specific primers. Lane (L) indicates the DNA 100 bp ladder, (Pos) is positive control, (Neg) is negative control, lanes 1,2,3,5 are isolates from sheep, lane (4) isolate from goat. Amplicons of PLD gene detected in al tested isolates at $203 \mathrm{bp}$ 


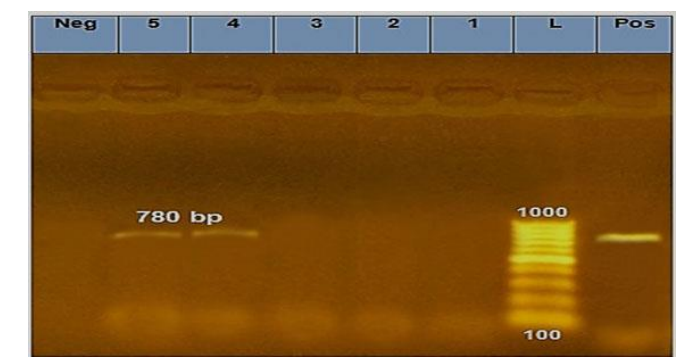

Figure 3 Agarose gel electrophoresis showing amplification product of $780 \mathrm{bp}$, of beta lactamase (bla) resistance gene of C. pseudotuberculosis performed with specific primers Lane (L) indicates the DNA 100 bp ladder, (Pos) is positive control, (Neg) is negative control, lanes 1,2,3,5 are isolates from sheep, lane (4) isolate from goat. Amplicon (bla) gene was detected in lanes 4,5 ).

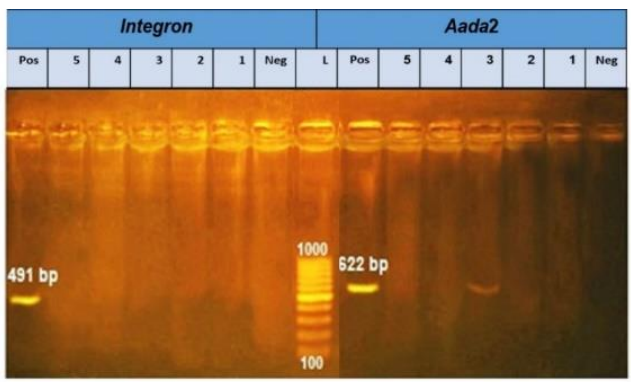

Figure 4 Agarose gel electrophoresis showing amplification product of integron 491 bp (negative in all isolates) and aminoglycoside (aadA2)resistance gene 622bp (positive in lane 3) of C. pseudotuberculosis amplified using specific primers. Lane (L) indicates the DNA 100 bp ladder, (pos) is positive control, (Neg) is negative control, lanes 1,2,3,5 isolates from sheep, lane (4) isolates from goat.

\section{DISCUSSION}

Caseous lymphadenitis disease of sheep and goat manifests itself in two forms the external and the internal forms. The most frequent of which is the external form of CLA, characterized by abscess formation in superficial lymph nodes and subcutaneous tissues (Baird and Fontaine, 2007). The external form of this disease results in decreasing general body performance, low production of wool and carcass condemnation (Arsenault et al., 2003)

In the current study, the investigation of the prevalence of external form of Caseous lymphadenitis resulted in overall prevalence of $13 \%$ in sheep and goat. These results are consistent with a previous study reported a prevalence of Caseous lymphadenitis in sheep and goat was $13.5 \%$ (Menzies and Muckle 1989). The prevalence of the $C$ .pseudotuberculosis in this study is somewhat higher than reported result in other locality in Egypt as a prevalence of $6.7 \%$ was reported in El-Gharbia governorate (Oreiby et al., 2014) .This variations in prevalence between the current study region and other region in Egypt may be attributed to the management system and climatic conditions in each region including the ambient temperature which affects the viability and spread of the bacteria (Al-Gaabary et al., 2010). Furthermore, the prevalence of the disease in sheep was $13.9 \%$ which is higher than its prevalence in goat $(8.6 \%)$ which may be attributed to the small cuts in the skin occurred during sheep shearing let sheep more prone to $C$. pseudotuberculosis infection. This trend of prevalence in small ruminant in the anterior part of the body is in agreement with previous result (Menzies and Muckle 1989).
In sheep the predilection site of $C$. pseudotuberculosis localization is mostly in the head region as out of 23 affected sheep, the distribution in lymph node was Mandibular 10 (43.5\%), Parotid $9(39.1 \%)$, Prescapular 3 $(13 \%)$ and prefemoral $1(4.3 \%)$. This is in agreement with previous study (Williamson 2001; pandey et al., 2007). This high rate of infection in the head lymph nodes more than the posterior body part indicates that the small wound resulted from shearing, head butting and grazing among sharp grass may be the route of $C$. pseudotuberculosis infection in sheep.

Antimicrobial susceptibility of $C$. pseudotuberculosis revealed high susceptibility to the Quinolones, Ciprofloxacin $65.4 \%$ followed by Norfloxacin $46.2 \%$ and Enrofloxacin $42.3 \%$. Indeed, in Argentina, quinolones have been recently reported to be effective on $100 \%$ of $C$. pseudotuberculosis isolates (Gallardo et al., 2018). This difference of the microorganism susceptibility to Quinolones may be attributed to the differences in antibiotics regimes used in treatment of bacterial infection or even the use of antibiotics as growth promoters in intensive production in livestock or even in broiler that led to the emergence of Quinolones resistance genes in the environment that by somehow find their way to be transformed to pathogenic bacteria including $C$. pseudotuberculosis. On the other hand, the isolates high resistance to beta lactames Amoxy. + clav. $57.6 \%$ followed by Amoxicillin 53.8\% in addition to the Aminoglycoside, Gentamycin $42 \%$ is in accordance with the recently observed low activity of $\beta$-lactam and aminoglycoside (Gallardo et al., 2018).

Surprisingly, the isolates resistance to the phenicol member, Florfenicol is only about 20\%. The high susceptibility of $C$. pseudotuberculosis isolates to phenicol in this study is in accordance with the increased sensitivity pattern of bacteria to chloramphenicol that was recently reported from study in Egypt, where $92 \%$ of the salmonella isolates were sensitive to chloramphenicol (Hammad et al., 2011). This is in line with the assumption drown by (Tatavarthy et al., 2012) that antibiotic recycling by reusing traditional first-line drugs (e.g., tetracycline, chloramphenicol, and trimethoprim) should be carefully considered. This may indicate changing trends in the antibiograms of all bacteria especially $C$. pseudotuberculosis isolates in Egypt. This probably demands reconsideration for the use of chloramphenicol in C. pseudotuberculosis infection treatment instead of ciprofloxacin or third and fourth generation Cephalosporins in light for the increasing resistance to quinolones and Blactames. Moreover, continuous monitoring of resistance patterns is essential for successful treatment of $C$. pseudotuberculosis infection between animals or human.

Searching for the virulence genes of $C$. pseudotuberculosis, we found that all tested isolates express the virulence gene Phospholipase D $(P l d)$. This genes is responsible for the production of the protein phospholipase which is an exotoxin dissociate the cell membrane sphingomyelin and hence increase the vascular permeability leading to spread of C. pseudotuberculosis and its invasion to the tissue and hence its transportation through the macrophage to the regional lymph nodes (Baird and Fontaine 2007, Corrêa et al., 2018 ). 
Thus, $P l d$ is considered the most important virulence factor in the pathogenesis of $C$. pseudotuberculosis-produced diseases (Hodgson et al., 1999). This result indicates the virulence nature of all tested isolates that we picked from sheep and goat lesion.

Concerning the antibiotic-resistance genes the investigation of the expression of these genes in the selected isolates revealed the absence of the integron from all isolates. This result is in agreement with a recently reported results of negative results for integron amplification in $100 \%$ of $C$. pseudotuberculosis isolates (Gallardo et al., 2018).

Searching for the $\beta$-lactames resistance gene (bla) revealed the presence of the gene in only two out of five isolates (40\%) which is consistent with the results of the antibiotic susceptibility test that the bacteria under study are resistant to most of the beta lactames members. In vitro exposure of $C$. pseudotuberculosis isolates showed that the microorganism was highly susceptible to $\beta$ - lactames (Judson and Songer 1991). However, the current study results indicate the gradual decreasing susceptibility of $C$. pseudotuberculosis to this drug family in accordance with a recent study showing the microorganism low susceptibility to $\beta$-lactames (Gallardo et al., 2018). These results may suggest the acquisition of resistance gene due to continuous exposure of the micro-organism to the $\beta$ - lactames as we found that some isolates have developed the ability to express the bla gene.

The aminoglycosides resistant gene amplification in the selected isolates revealed the expression of the aadA2 gene in two out of five isolates which is consistent with low susceptibility of $C$. pseudotuberculosis in the current study as $42 \%$ of the isolates proved to be resistant to gentamycin. This result also is in parallel with a recently presented data (Gallardo et al., 2018). Indeed, gentamicin was shown to be effective on the majority of $C$. pseudotuberculosis isolates (Connor et al., 2000). However, the present data indicates the emergence of aminoglycosides resistant gene detected in this study as aadA2 gene.

\section{CONCULSION}

A right control measure is required to prevent spread of abscessation between small ruminant as grazing among sharp objects and vigorous shearing to guard against producing entrance of the bacteria to the body. The current study revealed the change of the $C$. pseudotuberculosis susceptibility to the antimicrobial effect than previous report These results may necessitate the reconsideration of the general $C$. pseudotuberculosis management protocol based on the current situation which seem to be also specific for each locality depending on the previous exposure to antibiotic regimes for controlling $C$. pseudotuberculosis or other microorganism.

\section{REFERENCES}

1. Abdelazeem, M. Algammal, 2016. Molecular Characterization and Antibiotic Susceptibility of Corynebacterium pseudotuberculosis isolated from sheep and goats Suffering from caseous lymphadenitis. Zagazig Veterinary Journal. 44:1, 1-8.

2. Al-Gaabary, M. H., Salama, A., Osmana., Mohamed, S. and Oreiby, A. F., 2010. Abattoir survey on caseous lymphadenitis in sheep and goats in Tanta, Egypt. Small Ruminant Research. 94, 117-124.

3. Arsenault, J., Girard, C., Dubreuil, P., Daignault, D., Galarneau, J. R., Boisclair, J., Simard, C.and Bélanger, D. 2003. Prevalence of and carcass condemnation from maedivisna, paratuberculosis and caseous lymphadenitis in culled sheep from Quebec, Canada. Prev Vet Med. 59, 67-8.

4. Baird, G. J. and Fontaine, M.C., 2007. Corynebacterium pseudotuberculosis and its role in Ovine Caseous Lymphadenitis. J. Comp. Pathol. 137,179-210.

5. Baraúna, R. A., Ramos, R.T. J., Veras, A.A.O., deSáP, H.C.G., Guimarães, L.C., das Graças, D. A., Carneiro, A.R., Edman, J. M., Spier, S.J., Azevedo, V. and Silva, A., 2017. Genomic analysis of four strains of Corynebacterium pseudotuberculosis biovar Equi isolated from horses showing distinct signs of infection. Stand Genomic Sci. 31, 12-16.

6. Catalán, A., Espoz, M.C., Cortés, W., Sagua, H., González, J. and Araya, J.E., 2010.Tetracycline and penicillin resistant Clostridium perfringens isolated from the fangs and venom glands of Loxosceles laeta: its implications in loxoscelism treatment. Toxicon. 56, 890-896.

7. CLSI, 2015. Methods for antimicrobial dilution and disk susceptibility testing of infrequently isolated or fastidious bacteria. In., 3rd edn.Wayne: Clinical and Laboratory Standards Institute.

8. Connor, K.M., Quirie, M.M., Baird, G. and Donachie, W., 2000. Characterization of United Kingdom isolates of Corynebacterium pseudotuberculosis using pulsed-field gel electrophoresis. J. Clin. Microbiol. 38, 2633-2637.

9. Corrêa, J.I., Stocker, A., Trindade, S.C., Vale, V., Brito, T., Bastos, B., Raynal, J.T., de Miranda, P. M., de Alcantara, A.C., Freire, S.M., Costa, L.M. and Meyer, R., 2018 In vivo and in vitro expression of five genes in Corynebacterium pseudotuberculosis virulence. AMB Express, 8: 89-97

10. Dorella, F.A., Pacheco, L.G.C., Oliveira, S.C., Miyoshi, A and Azevedo, V., 2006. Corynebacterium pseudotuberculosis: microbiology, biochemical properties, pathogenesis and molecular studies of virulence. Vet Res. $37,201-218$.

11. Fontaine, M.C. and Baird, G.J., 2008. Caseous lymphadenitis. Small Rum. Res. 76, 42-48.

12. Gallardo, A. A., Toledo, R.A., González, Pasayo, R.A., Azevedo, V., Robles, C., Paolicchi, F.A., Estevao and Belchior, S.G., 2019. Corynebacterium pseudotuberculosis biovar ovis: Evaluation of antibiotics susceptibility in vitro]. Revista Argentina de Microbiologia, 20 Feb 2019, 51(4):334338

13. Hammad, O.M., Hifnawy, T., Omran, D.E.1., Tantawi, M.A. and Girgis, N.I., 2011. Ceftriaxone versus Chloramphenicol for Treatment of Acute Typhoid Fever. Life Sci. J., 8 (2): 100-105

14. Hodgson, A. L., Carter, K., Tachedjian, M., Krywult, J., Corner, L.A., McColl, M.and Cameron, A., 1999. Efficacy of an ovine caseous lymphadenitis vaccine formulated using a genetically inactive form of the Corynebacterium pseudotuberculosis phospholipase D. Vaccine. 17, 802-808.

15. Ilhan, Z., 2013. Detection of Corynebacterium pseudotuberculosis from sheep lymph nodes by PCR. Revue Méd. Vét., 164, 60-66.

16. Judson, R.and Songer, J.G., 1991. Corynebacterium pseudotuberculosis: In vitro susceptibility to 39 antimicrobial agents. Vet. Microbiol. 27, 145-150.

17. Menzies, P.I. and Muckle, C., A., 1989.The use of microagglutination assay for the detection of antibodies to Corynebacterium pseudotuberculosis in naturally infected sheep and goat flocks. Can J Vet Res. 53, 313-318.

18. Oreiby, A.F., Hegazy, Y.M., Osman, S.A., Ghanem, Y.M.and Al-Gaabary, M.H., 2014. Caseous lymphadenitis in small ruminants in Egypt. Clinical, epidemiological and 
prophylactic aspects. Tierarztl Prax Ausg G Grosstiere Nutztiere. 42, 271-277.

19. Pandey G. S. Nambota A. M. Muliokela L. Mubita D. M., 2007. Caseous lymphadenitis among recently introduced boer goats in Batoka, Zambia. The Indian veterinary journal 84(5): 461-462

20. Peel, M.M., Palmer, G.G., Stacpoole, A.M.and Kerr, T.G., 1997. Human lymphadenitis due to Corynebacterium pseudotuberculosis: report of ten cases from Australia and review. Clin Infect Dis. 2,185-191.

21. Qunin, P.j., Markey, B. K., Carter, M.E., and Carter G. R., 1994. Veterinary Microbiology and Microbiology, Mosby yearbook Europe limited, Lynton House, London. Pp. 109 126.

22. Santana-Jorge, K.T., Santos, T.M., Tartaglia, N.R., Aguiar, E.L., Souza, R.F., Mariutti, B., Eberle, R.J., Arni, R.K. Portela, R.W., Meyer, R.and Azevedo, V., 2016. Putative virulence factors of Corynebacterium pseudotuberculosis FRC41: vaccine potential and protein expression. Microb. Cell Fact. 16,15-83

23. Selim , S.A., 2001. Oedematous skin disease of buffalo in Egypt. J. Vet. Med. B infect. Dis. Vet. Public Health. 48, 241-258.

24. Soares, S.C., Silva., A., Trost, E., Blom, J., Ramos, R. Carneiro, A., Ali, A., Santos, A.R., Pinto, A.C., Diniz, C., Barbosa, E.G., Dorellam, F.A., Aburjaile, F., Rocha, F.S.,
Nascimento, K.K., Guimarães, L.C., Almeida, S., Hassan, S.S., Bakhtiar, S.M., Pereira, U.P., Abreu, V.A., chneider, M.P., Miyoshi, A., Tauch, A.and Azevedo, V., 2013. The pan-genome of the animal pathogen Corynebacterium pseudotuberculosis reveals differences in genome plasticity between the biovar ovis and equi strains. PLoS One. $28, \mathrm{e} 53818$.

25. Tatavarthy, A.1., Sanderson, R., Peak, K., Scilabro, G., Davenhill, P., Cannons, A. and Amuso, P., 2012 Molecular typing and resistance analysis of travel associated Salmonella enterica serotype Typhi. J. Clin. Microbiol. 50, 2631-2638.

26. Walker, R.A., Lindsay, E., Woodward, M.J.,Ward, L.R. and Threlfall, E.J., 2001. Variation in clonality and antibioticresistance genes among multiresistant Salmonella enterica serotype typhimurium phage-type U302 (MR U302) from humans, animals, and foods. Microb. Drug Resist. 7, 13-21.

27. White, P.A., McIver, C.J., Deng, Y. and Rawlinson, W.D., 2000. Characterisation of two new gene cassettes, aadA5 and dfrA17. FEMS Microbiol. Lett. 182, 265-269

28. Williamson, L.H., 2001. Caseous lymphadenitis in small ruminants. Vet Clin North Am Food Anim Pract. 17, 359 371, vii Review.

29. Windsor, P.A., 2011. Control of caseous lymphadenitis. Vet Clin North Am-Food Anim Pract. 27, 193-202. 